\title{
The Disruptive Technology That is Additive Construction: System Development Lessons Learned for Terrestrial and Planetary Applications
}

\author{
Michel R. Fiske ${ }^{1}$, Dr. Jennifer E. Edmunson ${ }^{2}$, and Edward G. Weite III ${ }^{3}$ \\ Jacobs Space Exploration Group, Huntsville, AL, 35806 \\ Mallory M. Johnston ${ }^{4}$ and John C. Fikes ${ }^{5}$ \\ NASA/Marshall Space Flight Center, Huntsville, AL, 35811 \\ Rob P. Mueller ${ }^{6}$ \\ NASA/Kennedy Space Center, FL, 32899 \\ William R. Robertson ${ }^{7}$ \\ Mississippi State University, Starkville, MS, 39659 \\ and \\ Dr. Behrokh Khoshnevis ${ }^{8}$ \\ Contour Crafting Corporation, El Segundo, CA, 90245
}

\section{Nomenclature}

$\begin{array}{ll}h & =\text { layer height } \\ g & =\text { gravitational constant } \\ \mu_{\mathrm{p}} & =\text { plastic viscosity } \\ \rho & =\text { density } \\ \mathrm{V} & =\text { velocity }\end{array}$

\section{Abstract}

Disruptive technologies are unique in that they spawn other new technologies and applications as they grow. These activities are usually preceded by the question, "What If?" For example, "What if we could use an emerging technology and in-situ materials to promote exploration on the Moon or Mars, and then use that same technology to keep our troops out of harm's way and/or help the worlds' homeless?" This question allows us to flip the mindset of "how can people create more valuable innovation?" to "how can innovation create more valuable people?." This approach allows us to view augmented human labor as an inclusive opportunity, not a threat.

The discipline of Additive Construction is growing rapidly due to the flexibility, speed, safety and logistics benefits offered as compared to standard construction techniques. Additive construction is a disruptive technology in that it employs the principles of additive manufacturing on a human habitat structure scale. Developed initially for

\footnotetext{
${ }^{1}$ In-Space Manufacturing, Technical Fellow, Advanced Materials \& Manufacturing, Exploration Technologies \& Systems Development Division, M/S ST23, AIAA Senior Member

${ }^{2}$ Planetary Geologist, Technical Fellow, Science \& Optics, Exploration Technologies \& Systems Development Division, M/S ST23

${ }^{3}$ Sr. Engineering Specialist I, Avionics \& Software Ground Systems Test Branch, M/S ES53. AIAA Member

${ }^{4}$ Deputy ACME Project Manager, Exploration Technologies \& Systems Development Division, M/S ST23

${ }^{5}$ ACME Project Manager, Exploration Technologies \& Systems Development Division, M/S ST23

${ }^{6}$ MSFC OSSI Intern (Planetary Habitat Design), Spacecraft \& Vehicle Systems Division, M/S EV32

${ }^{7}$ Senior Technologist, Swamp Works, Advanced Projects Development, M/S UB-R1, AIAA Member

${ }^{8}$ Founder \& CEO, 215 South Douglas St.
} 
emergency management and disaster relief applications, additive construction has now grown into military infrastructure and planetary (Moon and Mars) surface infrastructure applications as well.

Additive Construction with Mobile Emplacement (ACME) is a NASA technology development project that seeks to demonstrate the feasibility of constructing shelters for human crews, and other surface infrastructure, on the Moon or Mars for a future human presence. The ACME project will allow, for the first time, the 3-dimensional printing of surface structures on planetary bodies using local materials for construction, thereby tremendously reducing launch and transportation mass and logistics. Some examples of infrastructure that could be constructed using robotic additive construction methods are landing pads, rocket engine blast protection berms, roads, dust free zones, equipment shelters, habitats and radiation shelters. Terrestrial applications include the development of surface structures using Earth-based materials for emergency response, disaster relief, general construction, and housing at all economic levels.

This paper will describe the progress made by the NASA ACME project with a focus on prototypes and full scale additive construction demonstrations using both Portland cement concrete and other indigenous material mixtures. Rationale for the use of additive construction for both terrestrial and planetary applications will be explored and a thorough state-of-the-art of additive construction techniques will be presented. An evolutionary history of NASA's additive construction development efforts, dating back to 2004, will be included. The paper will then step through a series of trade studies performed to inform key processing and design decisions in the development of the full-scale ACES-3 system developed by NASA and the Jacobs Space Exploration Group for the U.S. Army Corps of Engineers (USACE) Construction Engineers Research Laboratory (CERL) in Champaign, IL. The selection of aggregate and binders, based on in-situ materials, will also be presented and discussed

\section{Introduction}

A disruptive technology is one that displaces an established technology and shakes up the industry or a groundbreaking product that creates a completely new industry. This term was coined by Harvard Business School professor Clayton M. Christensen [1]. Christensen separates new technology into two categories: sustaining and disruptive. Sustaining technology relies on incremental improvements to an already established technology whereas, as mentioned, a disruptive technology displaces an established technology.

So, what if custom designed houses could be completed in one day? It currently takes 6 to 9 months to construct an average house in the US.

What if we could build dignified but affordable housing constructed for low income populations? Nearly 30 million U.S. households face one or more of the following housing problems: cost burdens, overcrowding, and space inadequacy. Worldwide, while large cities in developing countries have been growing at rates nearing 5\% per year, slums and squatter settlements have been growing nearly twice as fast.

What if we could build comfortable and livable emergency shelters (not tents) constructed rapidly for long term usage by disaster victims? Currently it may take several months or years before disaster (earthquake, flood, war, etc.) victims are placed in permanent shelters.

What if we could execute this construction without waste and without noise, dust and emission pollution? Construction accounts for a significant amount of various harmful emissions and construction activities generate an exorbitant amount of waste. Construction of a typical single-family home generates a waste stream of about 3 to 7 tons. In terms of resource consumption, more than $40 \%$ of all raw materials used globally are consumed in the construction industry.

What if we could execute this construction with no accidents and injuries on construction sites with no related litigations? Labor injuries and fatalities happen frequently at construction sites. 400,000 workers get seriously injured or killed in construction annually in the U.S. alone, a country in which stringent safety codes are regulated.

Lastly, what if we could build new architectural designs giving new appearances to our homes, neighborhoods and cities? Any departure from standard designs (e.g., use of curvilinear features instead of straight walls) significantly increases the cost of conventional construction. 
During the 2018 World of Concrete exposition in Las Vegas, the corresponding author of this paper was asked repeatedly, primarily by members of the concrete and construction industries, if additive construction (AC) would put construction employees out of work. In fact, in the long term, AC can help solve many of the problems plaguing the construction industry including high accident rates at construction sites, low quality of work, difficulty of project management at construction sites, low labor efficiency, and a continuously declining supply of construction workers [2]. In addition, because formwork can account for as much as 35-54\% of total construction costs and consume 50$75 \%$ of total construction time [3], the use of AC could substantially reduce construction costs, improve productivity, and reduce the environmental impact by using less material and generating less waste. So, as in many cases, this instance of augmented human labor can be viewed as an opportunity for workers in new markets and education via a defined transition, as opposed to a threat to employment.

The informal motto of NASA Marshall Space Flight Center's In-Space Manufacturing group is “Make It, Don't Take It." NASA's planetary habitat manufacturing and assembly technologies that incorporate in situ resources provide options for autonomous, affordable, pre-positioned habitats with radiation shielding features and protection from micrometeorite and exhaust plume debris caused by launch and landing. Without a significant atmosphere, surface dust can be accelerated and cause substantial damage to adjacent structures unless precautionary measures like a wall or deflection berm are implemented. Not surprisingly, the U.S. military and emergency management organizations can realize many of these same benefits in the development of expeditionary structures and structures for disaster relief.

The ability to use in situ material to construct these structures either autonomously or with minimum personnel will allow payloads that would otherwise make long-term Moon and Mars habitation cost-prohibitive. Equally, the ability to use local materials to construct terrestrial military expeditionary structures or structures to support disaster relief or other emergency management applications autonomously or with minimum personnel will reduce transport of materials to local sites, reduce waste, and provide better overall ballistic protection and thermal conditioning performance than many standard military or other temporary construction techniques.

Since the term "additive construction" has been used also to describe automated methods for forming of molds and discrete layer deposition processes based on a particle bed approach, we make a distinction here to address only extrusion-based methods in this paper. Most AC processes utilize extrusion, whereby a mobility system (gantry, robotic arm, crane, etc) is used to position a nozzle in three dimensions to extrude a bead of cementitious material (typically $\sim 6 \mathrm{~mm}$ to $\sim 50 \mathrm{~mm}$ diameter). The print material is usually a mortar with high cement content and maximum aggregate size of between 0.039 " and 0.375 " diameter.

Like most additive processes, AC begins with an STL (standard triangulation language) file that is generated from a Computer-Aided Design (CAD) model and then divided into multiple 2D layers during a "slicing" process. Cartesian coordinates from the 2D layers along with printing parameters such as print head translation speed, pump speed, and extrusion flow rate are then sent to a 3D printer in machine-readable language (g-code). The desired structure is then printed layer by layer using the defined coordinates and the provided print rates. The primary difference between traditional additive manufacturing and $\mathrm{AC}$ is in the scale and the materials utilized.

On Earth, the term "in-situ materials" refers to local sources of the components of Ordinary Portland Cement (OPC)-based concrete, including sand, gravel, Portland cement, water, and both wet and dry additives. Using local materials minimizes the need to transport these materials in-theater. On the Moon and Mars however, in-situ materials refer to the materials on the planetary surface. These materials are typically inorganic (referred to as regolith to distinguish them from organic Earth soil) and will be the basis for the aggregate in any planetary cementitious material. The goal is to be able to extract a binder from the same material.

\section{Terrestrial Additive Construction}

Contour Crafting (CC) is an AC technology developed by Dr. Behrokh Khoshnevis of the University of Southern California and now also the Founder and CEO of Contour Crafting Corporation. This process is unique in that it shapes a continuously flowing bead of construction material, providing structural consistency and a more appealing aesthetic (Fig. 1 [4, 5], and Fig. 2). CC has been used to build structures of gypsum, Ordinary Portland Cementbased concrete, sulfur concrete and ceramic slurries [6,7], and has influenced almost every additive construction technology that has been developed since, as shown in Fig. 3 [8]. 


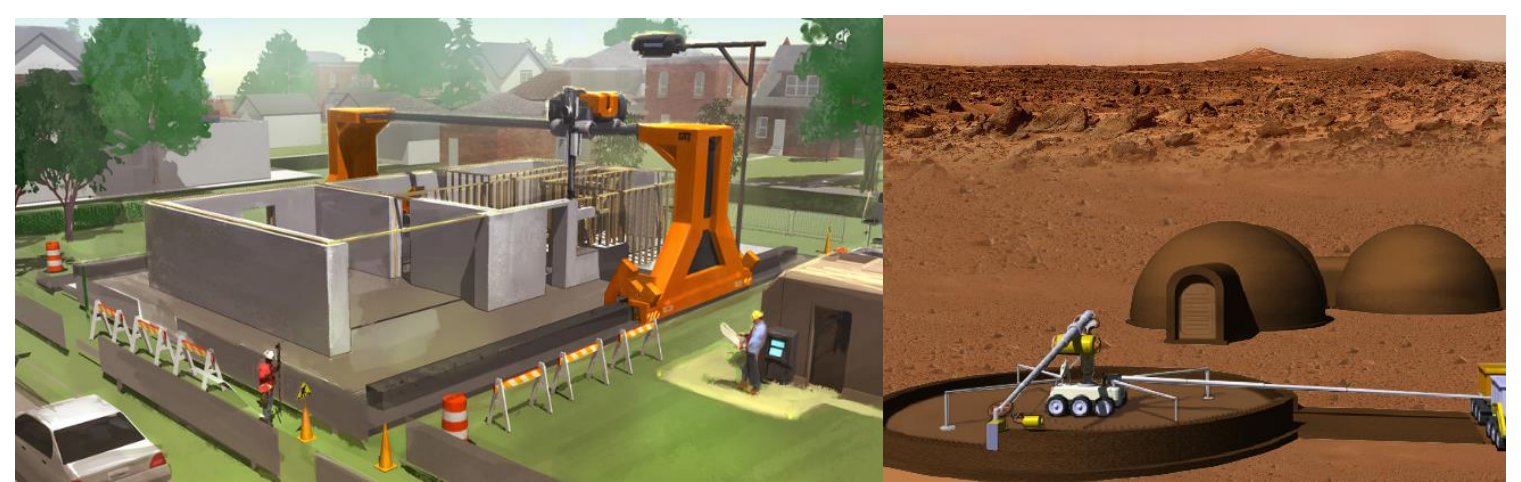

Fig. 1 Terrestrial and Planetary Representations of Contour Crafting. Image used with permission from Dr. B. Khoshnevis.

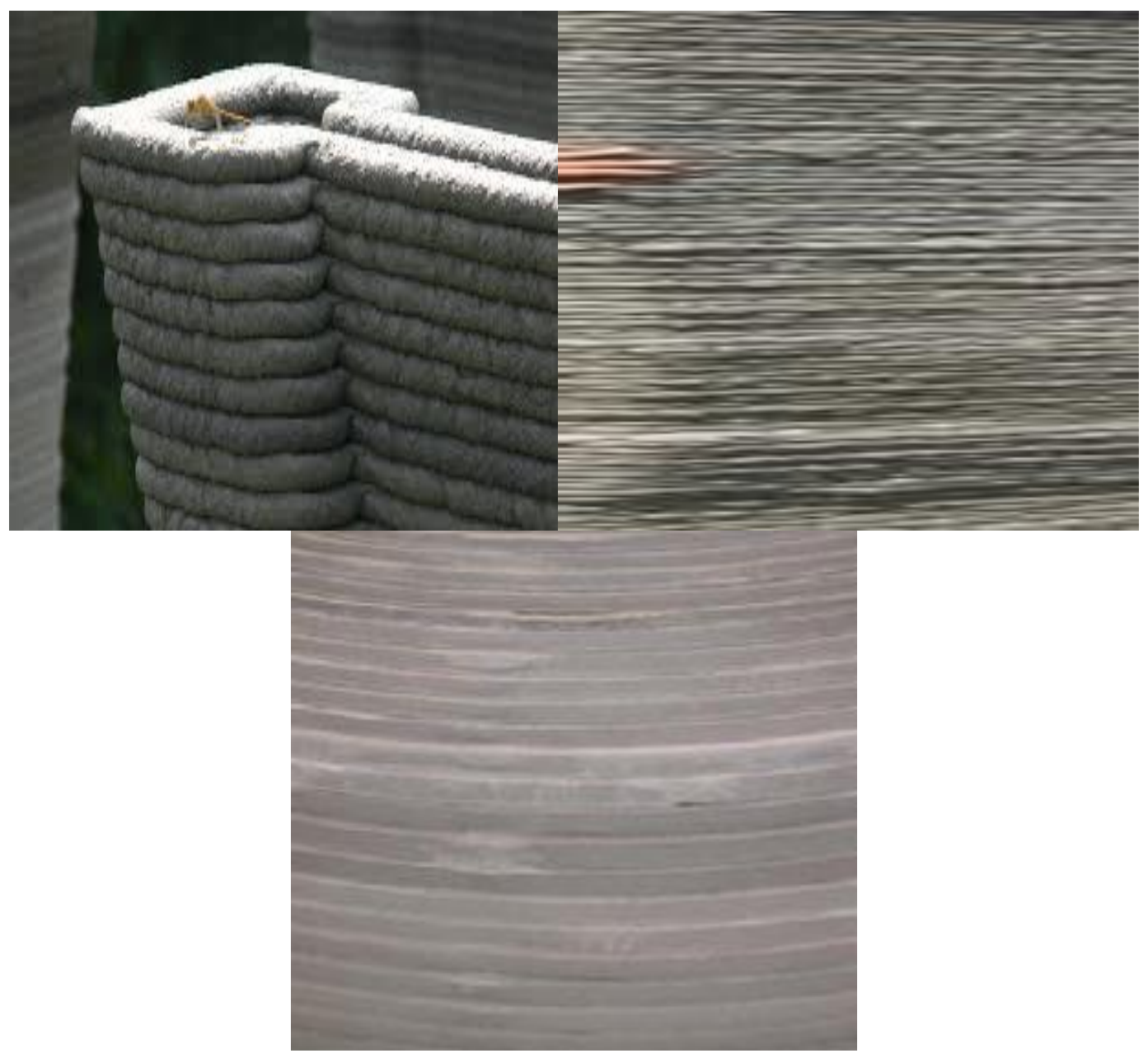

Fig. 2 Surface finish of (a, b) typical concrete deposition and (c) Contour Crafting deposition 


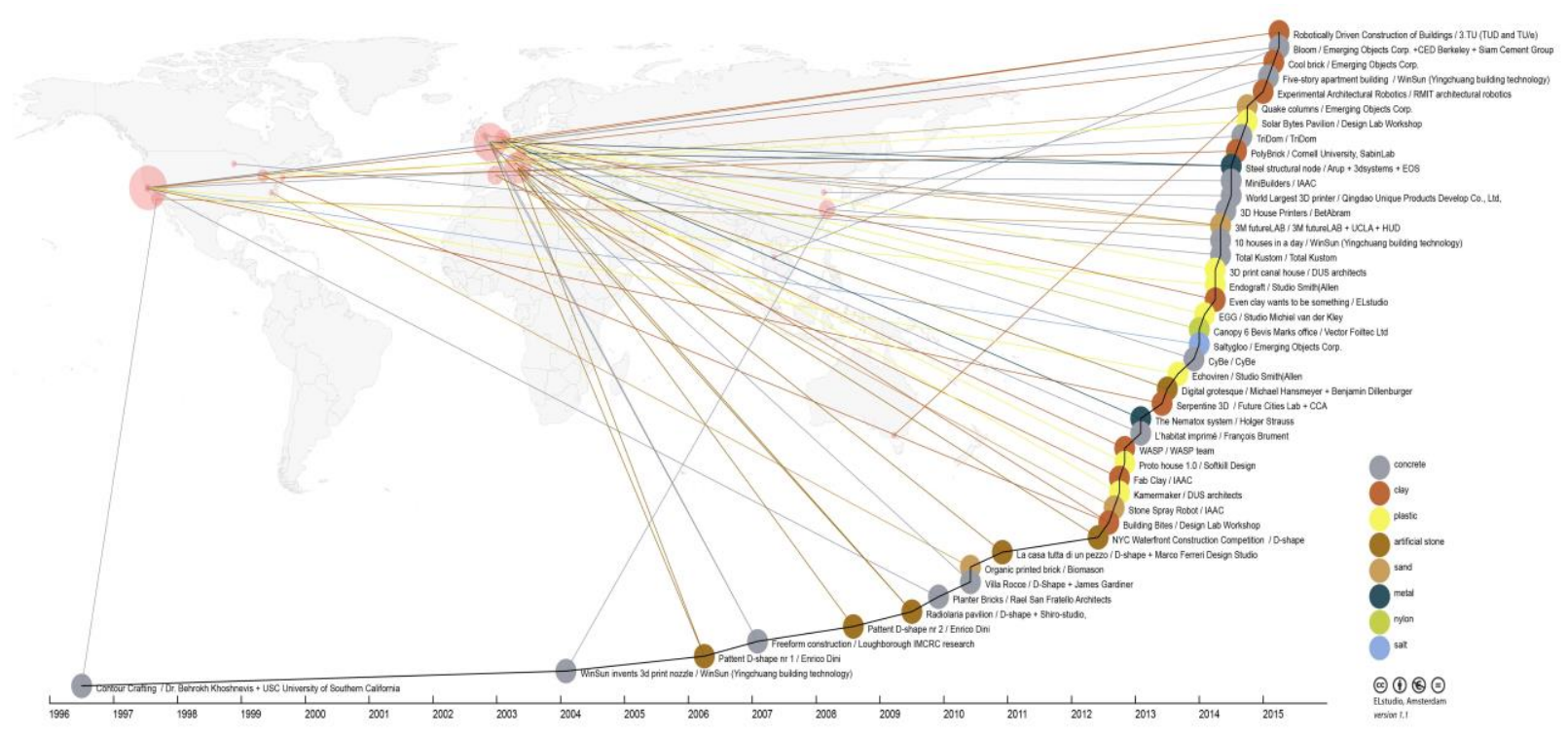

Fig. 3 The Exponential Growth of Additive Construction Since the Development of Contour Crafting. Image is used with permission of author via license at https://creativecommons.org/licenses/by-nc-nd/4.0/

Recently, the NASA/Jacobs Space Exploration Group (JSEG) team delivered a full-scale additive construction system to the U.S. Army Corps of Engineers (USACE) Construction Engineering Research Laboratory (CERL) in Champaign, IL. This system, known as Automated Construction of Expeditionary Structures (ACES-3), was based on prior work performed at NASA Marshall Space Flight Center (MSFC) from 2004-2007 and again from 20132017 during MSFC's Additive Construction with Mobile Emplacement (ACME) project. Funded by the USACE and NASA's Game Changing Development Program, ACME's mission was to develop a fundamental understanding of AC, evolving from batch processing to a continuous-feed system, and development of cementitious materials based on planetary (Moon and Mars) resources as well as understanding and controlling the rheological (viscosity) properties of these cementitious materials.

USACE is interested in the CC additive construction technology because of its ability to support development of on-demand structures in a variety of setting using local materials. These structures can include standard Army BHuts (troop housing), guard shacks, culverts, anti-tank obstacles, other barriers, etc. In addition, it is expected to take less time to build a B-Hut (16' x 32' x 8') using AC than when using traditional construction methods (one day vs. five days). AC may need fewer construction personnel and fewer security personnel to protect the construction workers. It reduces the amount of material brought into the field (we anticipate a $50 \%$ reduction) and can reduce waste from about one ton to less than 500 pounds per B-Hut. Another advantage is that if the Army has an agreement with a foreign government resulting in that government keeping the structures when the Army leaves, those structures can be designed and printed to reflect local architectures. Army forward personnel would all benefit from these improvements.

In 2004, USC delivered a Contour Crafting system to NASA MSFC that supported batch processing of OPCbased mixtures The system known as ACME-1 allowed fabrication of relatively long slender walls and, after some structural modifications, more complex geometries as well. Typical structures fabricated with ACME-1 include a dome structure with interior walls (Fig. 4) [9].

Between 2004 and 2007, the NASA/Jacobs team experimented with different nozzle and trowel configurations, initial characterization of optimum rheological ("soft solids") properties, and understanding the differences between commercial off-the-shelf concrete materials vs Portland cement, stucco, additives, etc.). Several different configurations and complexities of nozzles tested are shown in Fig. 5. We also spent significant effort programming and printing various geometries and experimenting with concrete deposition speed vs. concrete cure time and strength to optimize the overall process. 

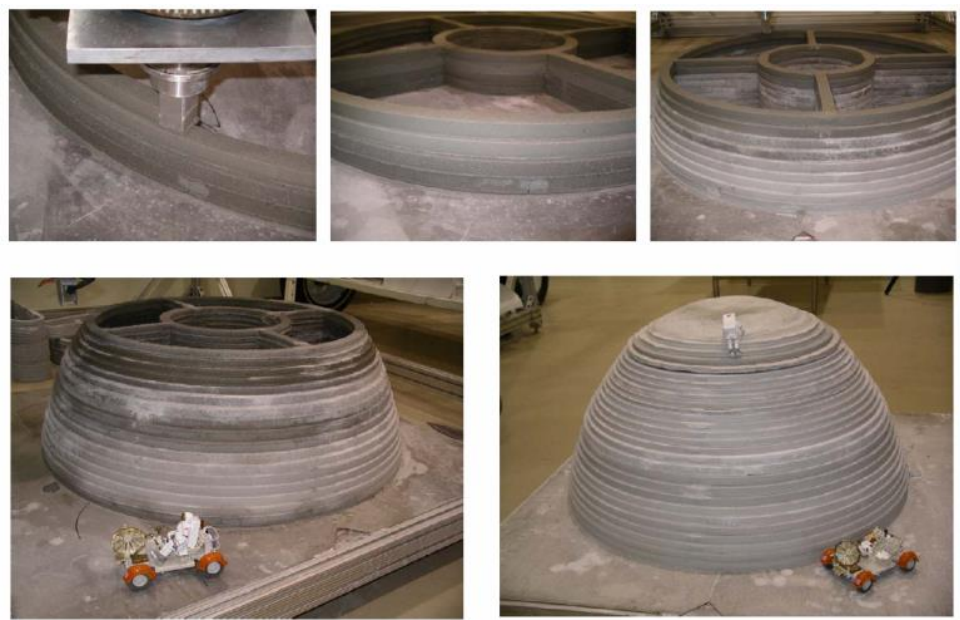

Fig. 4 Dome Structure with Interior Walls Printed on the ACME-1 System

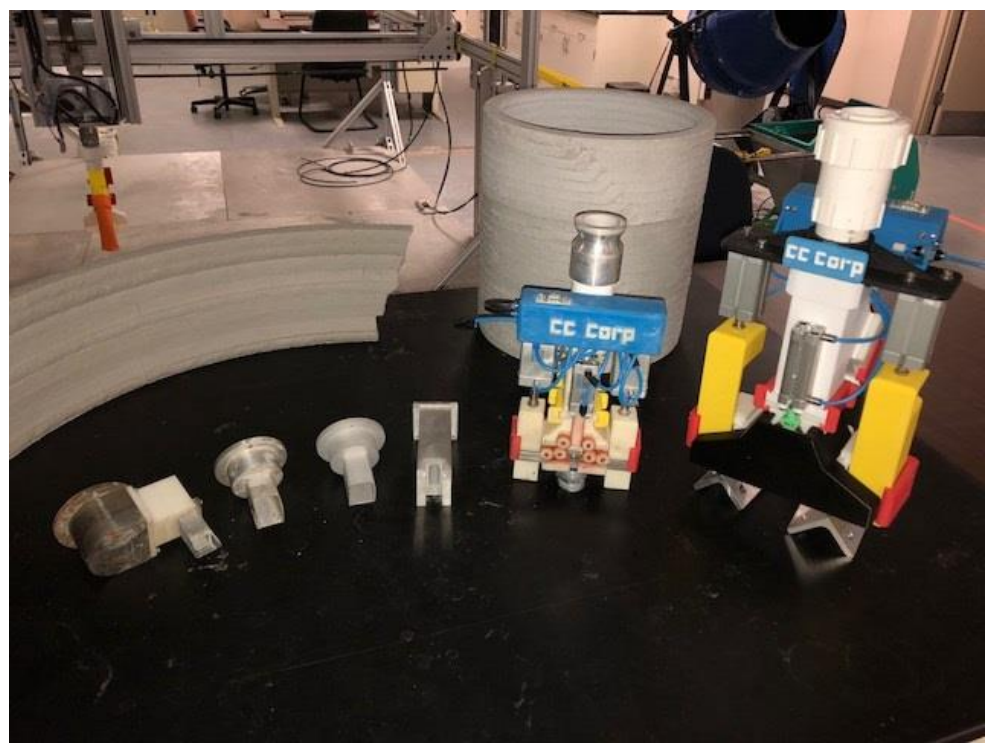

Fig. 5 ACME Nozzle Evolution - single and multiple output nozzles

The project was inactive from 2007 until 2013 when the USACE contacted MSFC to express interest in continued development of the ACME-1 system, specifically converting it from a batch process to a continuous-feed process (ACME-2). During batch processing, layers deposited on different days (wet on dry) did not adhere well and resulted in "cold joints", but same-day runs (wet on wet) yielded excellent bond strength. A cold joint can occur when successively deposited layers of concrete do not bond well. This can occur if a critical resting time is exceeded [10] and defines a maximum time for a layer to be produced to preclude these cold joints. For a specific material system and print geometry, the minimum linear production velocity required to avoid cold joints is given by [11]:

$$
\mathrm{V}>\left(\rho^{*} \mathrm{~g} * \mathrm{~h}^{2}\right) /\left(4 * \mu_{\mathrm{p}}\right)
$$

This continuous-feed system produced larger (but still sub-scale) structures, eliminated poor layer-to-layer bonding between batches, and eliminated discontinuities between the end of one batch and the beginning of the next batch. In concert with these activities, the design of the full-scale ACES-3 system began. The evolution from ACME-2 (NASA) to ACES-3 (USACE) focused on the transition from sub-scale to full scale. NASA/Jacobs 
worked with the USACE to define requirements for the ACES-3 system that reflected the USACE additive construction performance goals. Some of the key requirements included:

- Break the system down for transportation into no more than three $8^{\prime}$ x $8^{\prime}$ x $20^{\prime}$ volumes consistent with a standard Army Palletized Loading System (PLS)

- Complete system set-up and alignment in less than 11 hours

- Print in the $\mathrm{X}$ and $\mathrm{Y}$ axes at up to $500 \mathrm{in} / \mathrm{min}$ concrete deposition speed with a volumetric flow rate of up to 800 $\mathrm{in}^{3} / \mathrm{min}$

- Maintain absolute nozzle positional accuracy of $+/-1 / 8^{\prime \prime}$ in all three axes during printing

- Operate entire system with no more than six personnel (long-term goal of three)

- Print concrete with aggregate up to $3 / 8^{\prime \prime}$ diameter

- Include an automated dry goods storage and feed system for up to seven dry materials and an automated liquids storage and feed system for up to five liquid materials.

Many areas were identified as requiring further technology development and detailed evaluation, including:

- Selection of an optimized nozzle mobility system (gantry vs truck/boom arm vs robotic arm vs other)

- Selection of components for the larger system (pump, motors, drive system, etc.) to meet print speed and volumetric flow rate requirements

- Instrumentation (motor speed \& position, limit switches, etc.)

- Hose management (minimizing vertical pumping, curves, and hose length)

- Nozzle and accumulator design for better flow control and accommodation of large aggregate

- Positional accuracy

- System mobility

- Cleaning/waste management

- Assembly/disassembly

A series of trade studies were performed resulting in the selection of gantry system architecture and various hardware components and systems. Some of these trade studies are identified in Table 1.

Table 1 ACES-3 Gantry System Trade Studies

\begin{tabular}{|l|l|l|}
\hline Trade Study Performed & Options Considered & Selected Option \\
\hline Optimized Mobility System & $\begin{array}{l}\text { SCARA Platform } \\
\text { Cylindrical Coordinate Platform (i.e., Apis Cor) } \\
\text { Articulated Arm Platform (i.e., MIT DCP) } \\
\text { Stewart and Delta Robot Platforms } \\
\text { Cable-Suspended Platform (i.e., Skycrane) } \\
\text { Cartesian (Gantry) Platform (i.e., ACME-2, ACES-2) } \\
\text { Structure-Riding Platform }\end{array}$ & \\
\hline Control System Architecture & $\begin{array}{l}\text { PC/104 Utilizing Linux Computer Numerical control } \\
\text { (CNC) } \\
\text { Ruggedized PC } \\
\text { Windows-Based }\end{array}$ & PC/104 Utilizing Linux CNC \\
\hline Drive Motor Selection & $\begin{array}{l}\text { Servo Motors } \\
\text { Stepper Motors }\end{array}$ & \\
& & $\begin{array}{l}\text { Servo Motors for all X and Y axis and Z } \\
\text { (coarse) motors } \\
\text { Stepper Motors for Z axis (fine) and nozzle } \\
\text { rotation motors }\end{array}$ \\
\hline Concrete Pump Selection & $\begin{array}{l}\text { Electric or Gas/Diesel Piston Pump } \\
\text { Electric or Gas/Diesel Progressive Cavity Pump } \\
\text { (over a dozen pumps/vendors evaluated) }\end{array}$ & $\begin{array}{l}\text { IMER Step-Up 120 Electric Progressive } \\
\text { Cavity Pump }\end{array}$ \\
\hline Limit Switch Type & $\begin{array}{l}\text { Mechanical Switch } \\
\text { Hall Effect Sensor }\end{array}$ & Hall Effect Sensor \\
\hline
\end{tabular}

In AC, the hardware required to move the printhead in three axes is typically referred to as the mobility system. Terrestrially, the mobility system is typically comprised of either a gantry, robotic arm, or crane configuration. 
During development of the ACES-3 AC system, a detailed trade study of these and other mobility system configurations was evaluated for both terrestrial and planetary applications [12].

The advantage of using gantry and crane printers is that they are easily scalable in size. Robotic arms typically have a fixed dimension and are difficult to scale up. However, the speed and degrees of freedom provided by a 6axis robot allow it to perform many tasks that may not be possible with a 4-axis gantry printer. In addition, if the design of printed objects does not require any complexity, a gantry printer may be preferred over a robotic arm printer since the cost of a robotic arm of equivalent size is higher and the payload capability of a robotic arm is generally lower than on a gantry [13]. Lastly, positional accuracy tends to be higher with a gantry due to the oscillation resulting from a heavy mass on the end of a translating boom arm.

For ACES-3, a gantry system was developed, as shown in Fig. 6. This gantry consists of two parallel rail assemblies in the $\mathrm{X}$-axis. Each rail assembly is $\sim 54$ ' long and consists of three sub-assemblies bolted together that allows breakdown for packaging into previously-mentioned PLS volumes. The two rail assemblies are connected by two truss assemblies on each end. These can also be removed which enables the gantry to be pulled off of a completed structure to support short-distance transportation to a new build location. The rail assemblies include four casters each. The casters assist with towing the system from one build location to another. Multiple manually adjustable legs assist in fine levelling, which is performed using a laser levelling system. Coarse levelling is achieved through the use of an integrated, COTS recreational vehicle levelling system prior to fine levelling. X-axis translation is provided via alternating current (AC) servo motors and a chain drive that provides four-wheel drive to a trolley on each rail assembly. Encoders provide motor feedback, but each rail assembly also incorporates a laser rangefinder to provide independent measurement of gantry position.

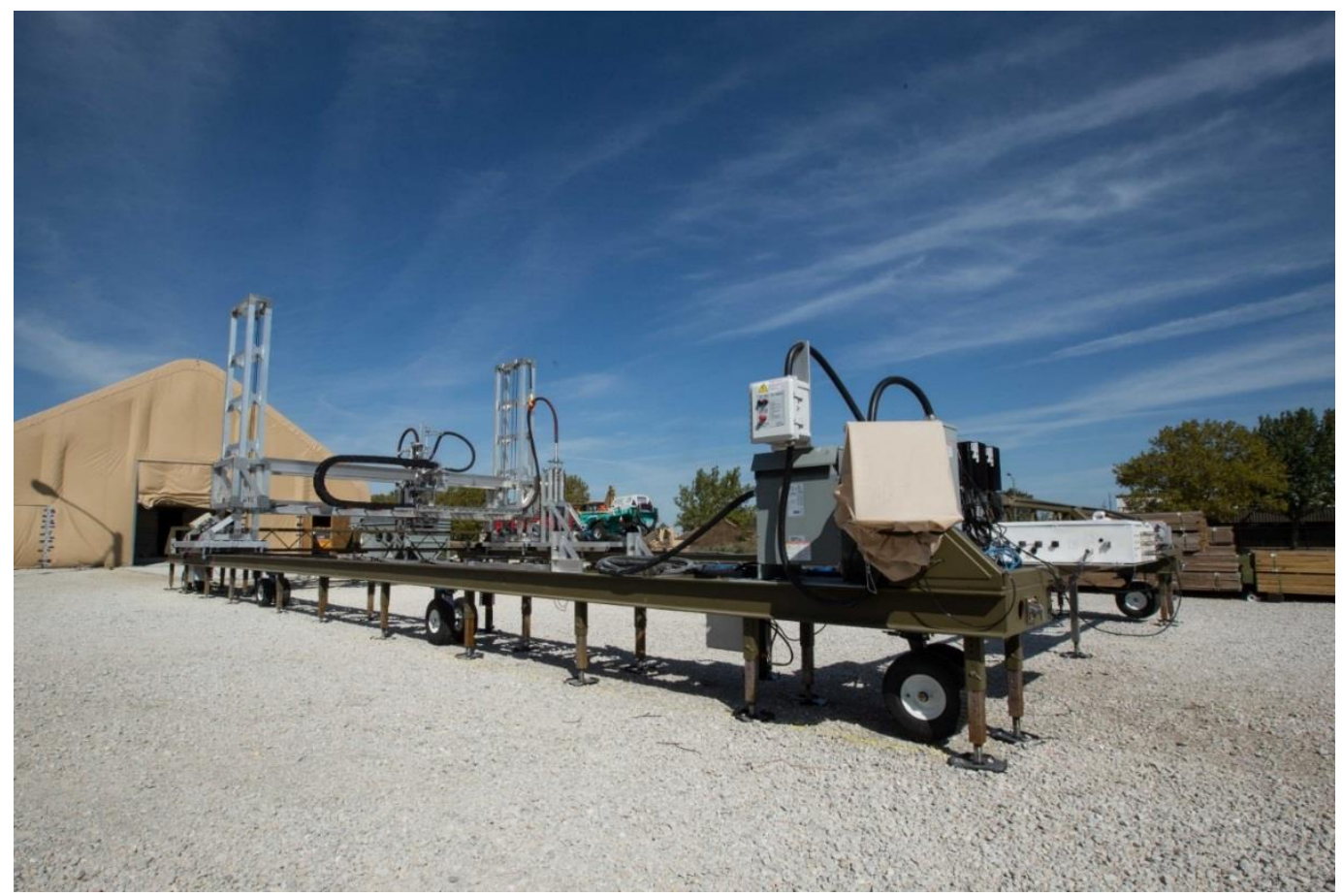

Fig. 6 ACES-3 System at USACE 


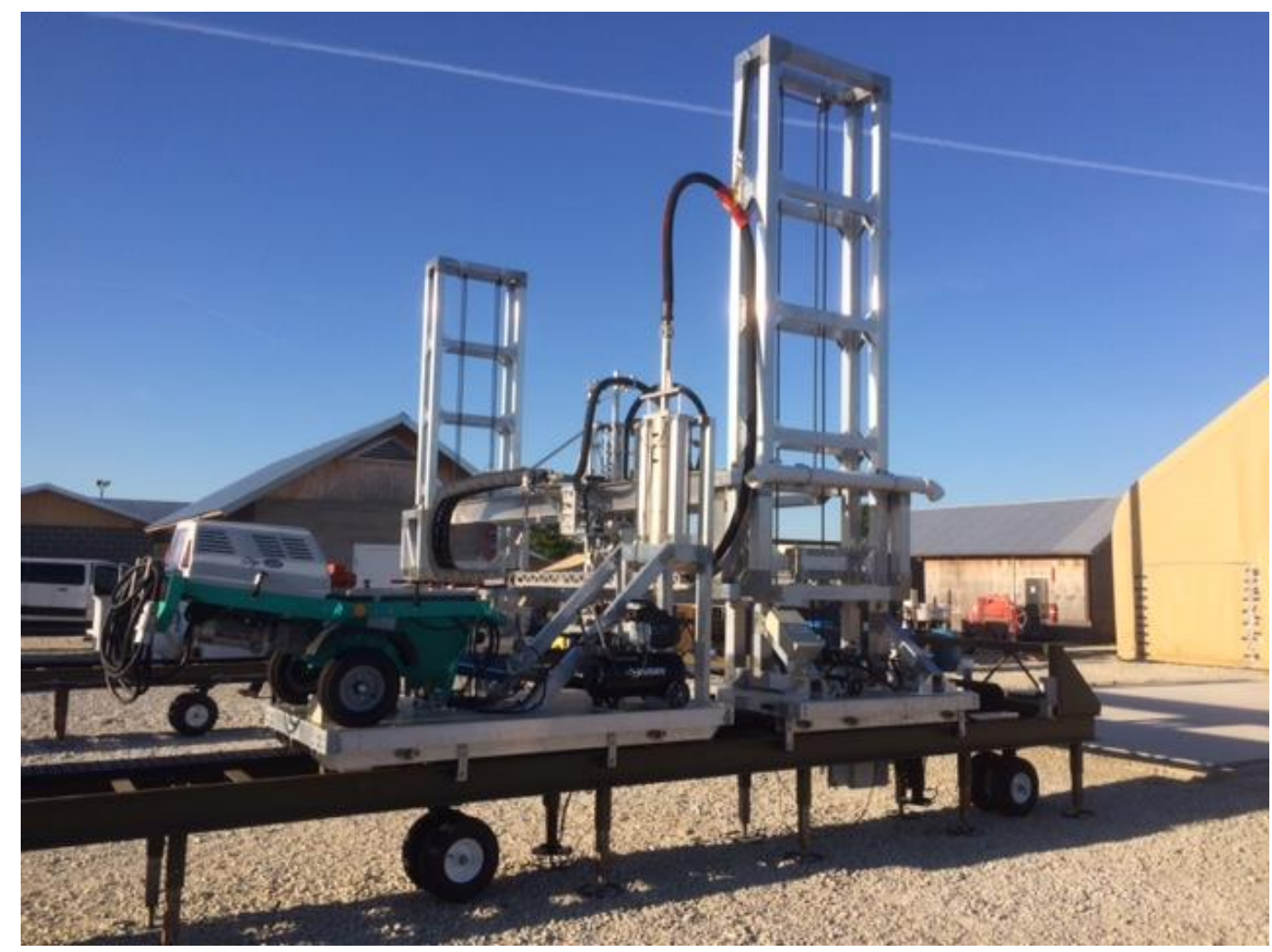

Fig. 7 ACES-3 System Pump/Accumulator Trolley

Controlling physical printhead (nozzle) placement to $1 / 8$ inch in 3 -space presents an interesting control issue. The mechanical tolerance buildup and any drive slippage within the 4,100 cubic foot build volume disqualified only the use of standard motor encoding mechanisms for position feedback. These specialty laser rangefinders provide absolute position; $20 \mathrm{~Hz}$ sampling, +/- $1 \mathrm{~mm}$ out to 100 meters.

ACES-3 physical size, environment and safety required that the switches used for limit and end-of-travel have a high level of robustness and redundancy. IP-67 rated Hall sensors were chosen to exceed the requirements and because of their zero wear characteristics (i.e., no physical contacts to wear). Redundant switch/magnet switch pairs were placed on each end of each axis.

Aluminum towers, approximately 14 ' tall, are mounted to each of the two gantry trolleys. These towers support a bridge that moves vertically in 4' increments. This "coarse $Z$ " positioning allowed designers to keep the boom/nozzle used for "fine Z" positioning to about a 4' length as well, reducing inertial flexibility and oscillations during rapid movement. The "coarse Z" positioning is performed by AC servo motors and chain drives mounted on the gantry trolleys while the "fine Z" positioning is generated via a COTS linear actuator driven by a stepper motor. Nozzle rotation is also performed via a stepper motor. The drive wheels roll on a composite friction material adhered to the top of the rail assemblies that is used to enhance acceleration and braking

A separate pump/accumulator trolley, shown in Fig. 7, moves in concert with the two gantry trollies. The trolley has an identical drive system to the two gantry trollies and is controlled simultaneously with them. An ultrasonic proximity sensor keeps the pump/accumulator trolley from getting too close or too far from the gantry trolley during rapid translation speed or direction changes. The IMER 120 progressive-cavity pump provides a continuous flow of concrete at rates from about 0.2 to 1.4 cubic feet/minute (CFM). The COTS IMER 120 provided two speeds, 0.6 or 1.24 CFM. A variable speed drive was integrated into the pump control system to provide a continuous and variable range of available flow rates, increasing flexibility of the overall system. Maximum pump speed is a function of nozzle cross-sectional area and translation rate. For a given configuration, a higher pump speed would result in a higher system pressure and swelling of the concrete bead as it exits the nozzle. Too low a pump speed would result in reduced system pressure and "necking" of the bead as it exits the nozzle. 
Concrete flows from the pump into an accumulator, also shown in Fig. 7. The accumulator has been designed to accumulate concrete to support the emplacement of a door or window into a structure being printed. This is done using a flow control valve on the nozzle that can be activated to stop flow of the concrete while the nozzle continues to translate. The accumulator has been sized to accumulate a volume of concrete equal to at least one 48 "- long layer of concrete being printed at a speed of $500 \mathrm{in} / \mathrm{min}$ and a volumetric flow rate of $800 \mathrm{in}^{3} / \mathrm{min}$. Two air cylinders fed by an on-board compressor provide sufficient resistance on the accumulator to allow accumulation, but will force concrete back out of the accumulator once the concrete flow is restored at the nozzle.

Fig. 7 also presents a view of the carriage and boom assembly, which includes the nozzle. Y-axis motion is provided by a carriage that rides on the four aluminum beams of the bridge assembly and is friction-driven by an AC servo motor. A laser rangefinder also provides independent confirmation of $\mathrm{Y}$-axis position. In the background, a large, black energy chain can be seen; this provides for consistent movement of wire bundles and the concrete supply hose. The hose management concept can also be clearly seen in Fig. $6 \&$ 7. Two support structures mounted on top of the carriage allow for movement of the hose in both $\mathrm{Y}$ and $\mathrm{Z}$ directions during printing while maintaining the industryrecommended minimum radius of curvature (as a function of hose diameter). All aspects of the hose management system are designed to support easy and rapid removal of any hose in the event of a concrete clog.

The ACES-3 nozzle, shown in Fig. 8, includes a flow control valve, as well as two trowels to allow independent control of the concrete finish on each side of the exiting concrete bead. This troweling feature is a hallmark of the Contour Crafting process, yielding structures with excellent surface finish as well as layer-to-layer bonding. The nozzle body is constructed of 3D-printed stainless maraging steel (high $\mathrm{Cr}$ ) to facilitate rapid replacement and to minimize environmental effects. The nozzle output is rectangular; one study concluded that the surface finish created with a square orifice is better compared to an elliptical orifice [14]. In addition, the ease of manufacture is reported to be greater with a square orifice rather than an elliptical one [15]. The nozzle control system interfaces with the overall ACES-3 control system.

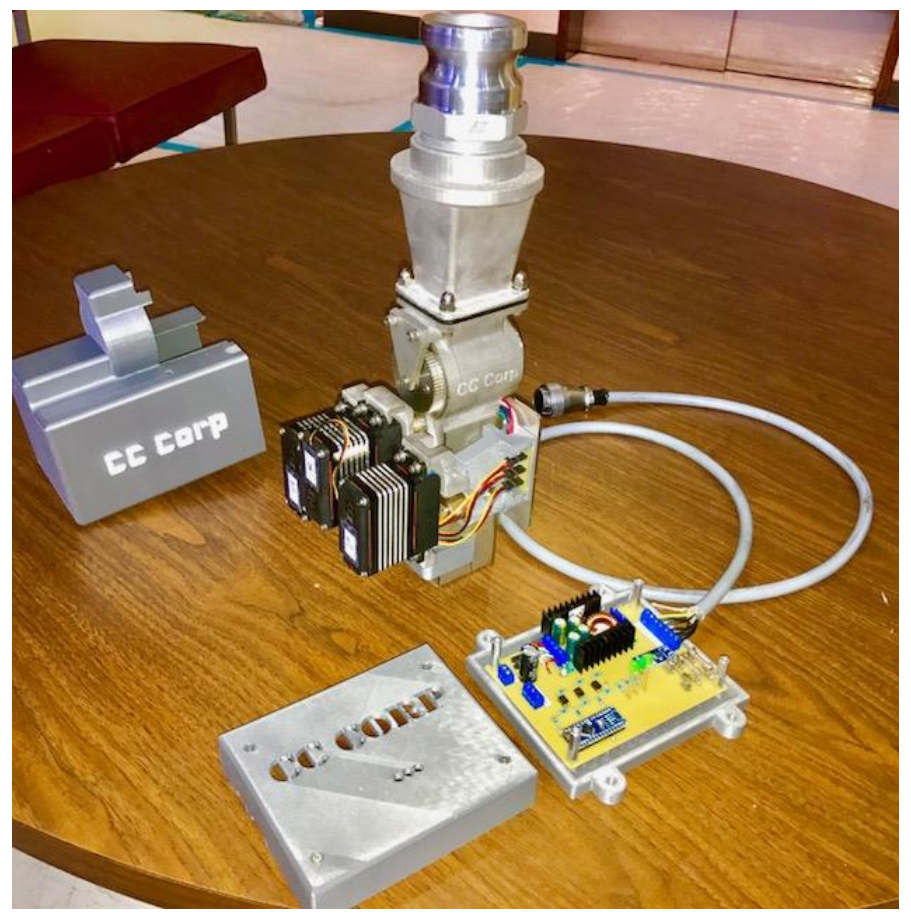

Fig. 8 ACES-3 Nozzle/Controller

A standard desktop computer with the required pluggable I/O cards would not meet the environmental requirements of ACES-3 (temperature, humidity, vibration, dust, etc.). PC/104 is a family of embedded computer standards which define a form factor and computer busses that lend themselves to such environmental concerns. In essence, $\mathrm{PC} / 104$ is a modular ruggedized version of a PC. Stackable interconnects allow the user to pick and choose I/O 
from a large vendor base to complete the complex control system required by ACES-3 to drive the six multihorsepower servo motors.

A high end laptop PC (Microsoft Windows 10) was chosen to host the structure design software (Autodesk Revit.) Output from the Revit design cycle was then the run through slicer software (open-source) used to produce the G-Code (RS-274) machine control program that directs the nozzle position.

AC servo motor drives consist of electrical current, velocity and position control loops. Tuning of these controllers to achieve satisfactory and consistent dynamic responses are crucial to maintaining control of the deposition of concrete. Using a software control system to accomplish this allows the system designer to vary these parameters quickly and efficiently. For such systems to operate, a Real Time Operating System (RTOS) is required. An RTOS is designed to provide predictable and repeatable performance within a given time constraint.

With our requirements for a G-code interpreter, servo drive with tunable control loops for six servo axes and control of two stepper axes with required realtime performance in hand, the search for COTS software to provide all of these features led us directly to LinuxCNC. "LinuxCNC" is a free, open-source GNU/Linux software system that implements numerical control capability using general purpose computers to control CNC machines" [16]. LinuxCNC volunteer developers provide design and support for a variety of hardware systems. Software distributions come bundled with patched versions of the Linux operating system providing the RTOS support and runs on PC computer hardware.

With the COTS software on a Windows laptop generating the G-code and LinuxCNC on PC/104 hardware performing the servo control loop and stepper drives, the system was created with COTS hardware and software and is being integrated on site at the USACE.

The Dry Goods and Liquid Goods Delivery Systems (DGDS and LGDS, respectively), designed and fabricated by NASA/Kennedy Space Center, are shown in Fig. 9. Note that the LGDS components are now completely integrated into the open space below the storage bins on the DGDS.
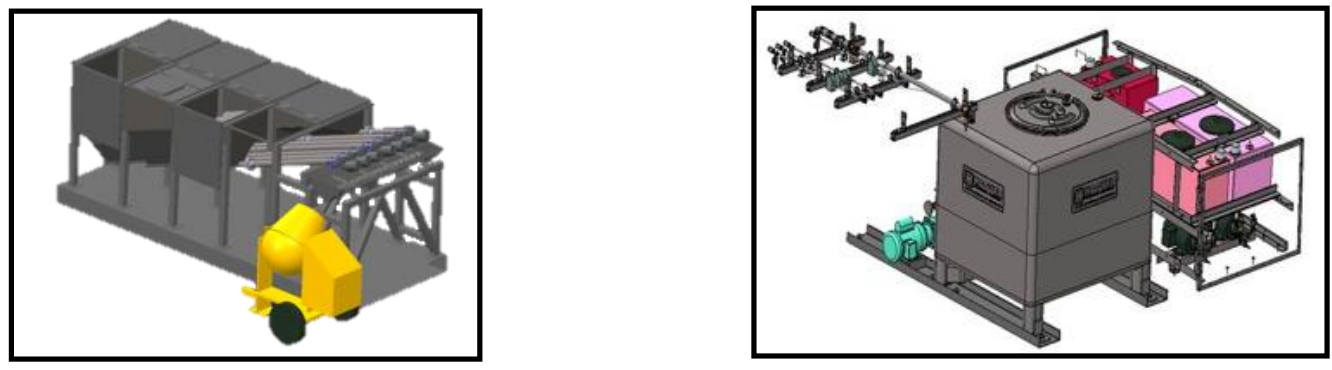

Fig. 9 ACES-3 DGDS and LGDS Design Models. Image used with permission from R. Mueller.

The ACES-3 system utilizes up to seven different dry goods such as Portland Cement, 3/8 inch gravel, coarse sand and fine sand as well as other specialty additives that must be metered and delivered in accurate doses to make a concrete mixture with suitable properties for 3D printing via the Contour Crafting nozzle. These dry goods must be mixed with water and up to four other admixtures to produce the final concrete slurry which has a suitable rheology for reliable printing. KSC developed a fully automated system that can supply the ingredients for any desired concrete mix recipe that is entered on a user interface touch screen. These materials are supplied to a "Scoop n Mix" apparatus which is mounted on a skid-steer loader to batch feed a concrete pump mounted on the ACES-3 gantry.

The DGDS, shown in Fig. 10 \& 11 [17] is a custom design which can store and accurately dispense up to seven different dry goods from steel hoppers via an automated computer controlled auger feed system. The dry goods are dispensed into a separate weigh hopper that is mounted on four load cells that inform the control system and operator of the dispensed dry goods mass. The design was driven by the requirement to be capable of delivering $\sim 0.63$ cubic yards of concrete per hour to the ACES-3 gantry to meet the extrusion speed requirement and the requirement of being able to package the DGDS/LGDS combination on an 8' x 8' x 20' PLS that can be loaded onto a C-130 aircraft or USACE flat rack truck for transportation.

11

American Institute of Aeronautics and Astronautics 


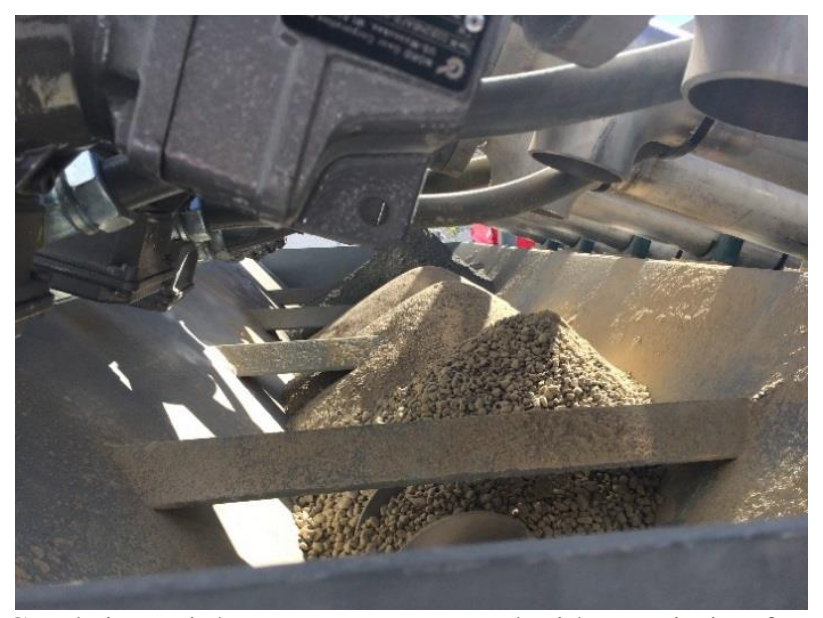

Fig. 10 Dry Goods in Weigh Hopper. Image used with permission from R. Mueller.

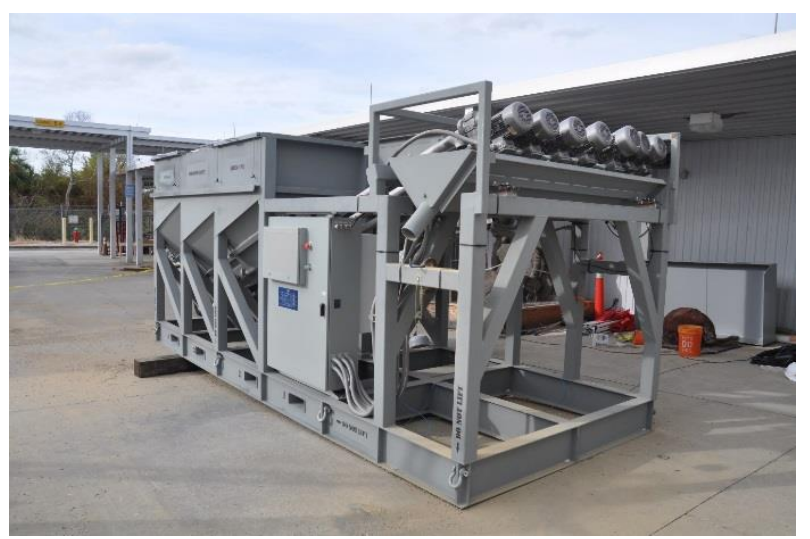

Fig. 11 Completed DGDS. Image used with permission from R. Mueller.

The LGDS is designed to automatically dispense water and up to four other admixtures to the dry goods mix. It has calibrated flow meters that measure the amount of each liquid as they are pumped out of a set of nozzles mounted at the "Scoop n Mix" interface, and are added to the mixer as the dry goods are also dispensed. The LGDS is integrated into the DGDS structural frame and control system.

\section{Terrestrial Construction Materials Development}

Most terrestrial AC technologies involve the deposition of cementitious material in a viscous liquid form via a printing nozzle, much like the Fused Deposition Modeling technique used with additive manufacturing of plastics. In both cases, solidification of the material is achieved by curing following extrusion. Typically, bulk materials are combined with a binding paste made of 1) cements consisting of mixtures of oxides of calcium, silicon and aluminum, or 2) a polymer blend to form "concrete-type" materials. The bulk materials typically consist of:

- Natural aggregates such as soil, sand, natural gravel, crushed stone, clay or mud

- Recycled aggregates such as those from construction, demolition, or excavation waste

- Manufactured aggregates such as air-cooled blast furnace slag and bottom ash

- Natural fibers, such as cellulose and recycled wood fiber [18]

In an effort to quantify process-related AC behavior, the following four extrusion-based characteristics have been identified [19]:

1) Pumpability: the ease and reliability with which material is moved through the delivery system

2) Printability (also known as "extrudability"): the ease and reliability of depositing material through a nozzle 
3) Buildability: the resistance of deposited wet material to deformation under loads

4) Open Time: the period during which the other three properties remain consistently within acceptable tolerances.

During the development of ACME-1 and again during ACME-2, a standard "recipe" was utilized to evaluate any new modifications, additives, etc. This recipe is presented in Table 2.

Table 2 Standard Terrestrial 3D Printing Mix

\begin{tabular}{|c|c|}
\hline Component & Amount \\
\hline Type I/II Ordinary Portland Cement (OPC) & $42 \mathrm{lbs}$ \\
\hline $\begin{array}{c}\text { Premixed Finish Coat Stucco Mix (25\% OPC, 75\% } \\
\text { sand) }\end{array}$ & $168 \mathrm{lbs}$ \\
\hline Water & $36.75 \mathrm{lbs}$ \\
\hline BASF Navitas & $200 \mathrm{gms}$ \\
\hline BASF MasterMatrix VMA 358 & $147 \mathrm{gms}$ \\
\hline BASF MasterSet DELVO & $61 \mathrm{gms}$ \\
\hline
\end{tabular}

As the ACES-3 system design progressed, this recipe was used to qualify pump operation (IMER Small 50 and Step Up 120 progressive cavity pumps), accumulator design (used to accumulate concrete when concrete flow was stopped at the nozzle to support window or door incorporation), hose configurations, and nozzle design/evaluation. This recipe consistently provided a standard slump value of $1.0-1.25$ inches and a measured plastic viscosity of 5 $20 \mathrm{~Pa}^{*}$ s (typically closer to $9-10 \mathrm{~Pa}^{*} \mathrm{~s}$ ).

During materials development, the application of heat was also considered. Some research shows that applying heat was effective in improving shape stability of fresh concrete, compared to a 10-minute delay. This can reduce the total construction time significantly [20].

Other research has shown that interlocking layers (for 0.25 " and 0.5 ") increased the bond at interfaces of the layers [21]. In this research, the bond strength for specimens with 0.5 " interlocking increased from $16 \%$ to $19 \%$ with an average of $17 \%$ in comparison with the base case under compression long layer interfaces (interlayer adhesion).

The concrete material mixture used by Winsun contains glass fibre, steel, cement, hardening agents and recycled construction waste materials. Note that the multiple houses built by WinSun were not fully 3D printed onsite. The structural elements were printed in segments in the factory and transported to the site, where they were assembled [22].

\section{Planetary Additive Construction}

Recent space habitat architecture work at MSFC has focused on the development of designs that provide radiation and ballistic protection, and maximize structural support by placing cementitious materials into compressive modes. A nominal habitat placed on the lunar surface and pressurized to $14.7 \mathrm{psi}$ can place significant tensile loads on the habitat structure. Judicious design can offset this tensile loading, can be connected to other structures, provides additional thermal mass, and can mitigate damage from the radiation environment and from micrometeorites. One such concept is shown in Figs. 12-14. Fig. 12 shows an additively printed (FDM) model of such a habitat. Fig. 13 presents two sections showing personal space in the upper half of the structure and of personnel. No attempt was made to optimize this structure for a certain number of personnel on the Lunar surface, the focus here was on the outer geometry as optimized for additive construction and the planetary environment. Lastly, Fig. 14 shows a representation of this structure common space, galley, access tunnels and lab space in the bottom. 


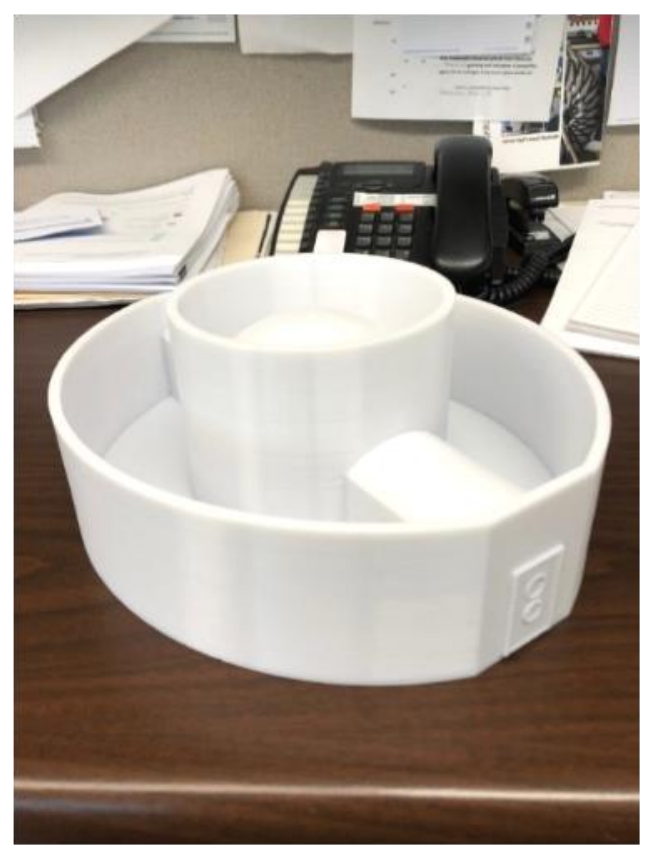

Fig. 12 Planetary Surface Habitat Design Concept for Additive Construction
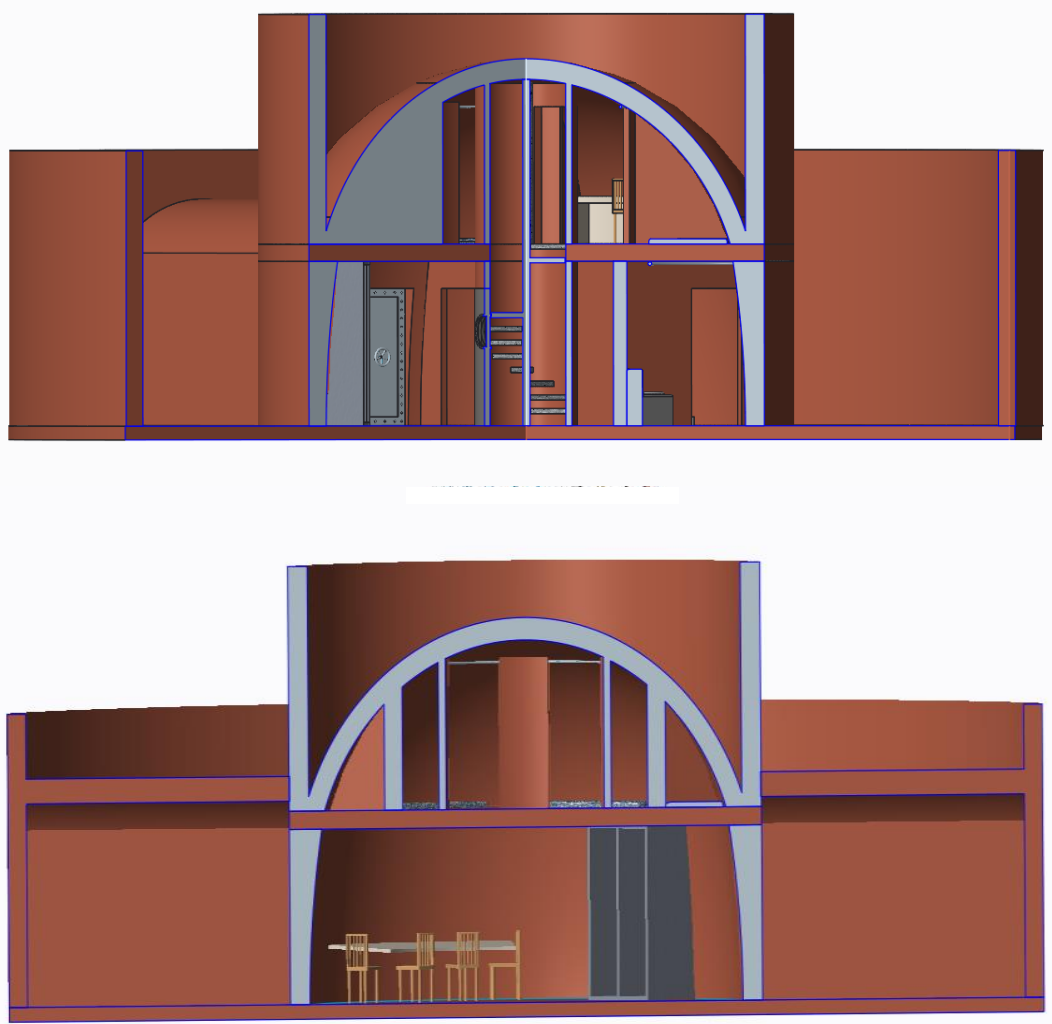

Fig. 13 Planetary Surface Habitat Design Concept for Additive Construction - Cross-sections 


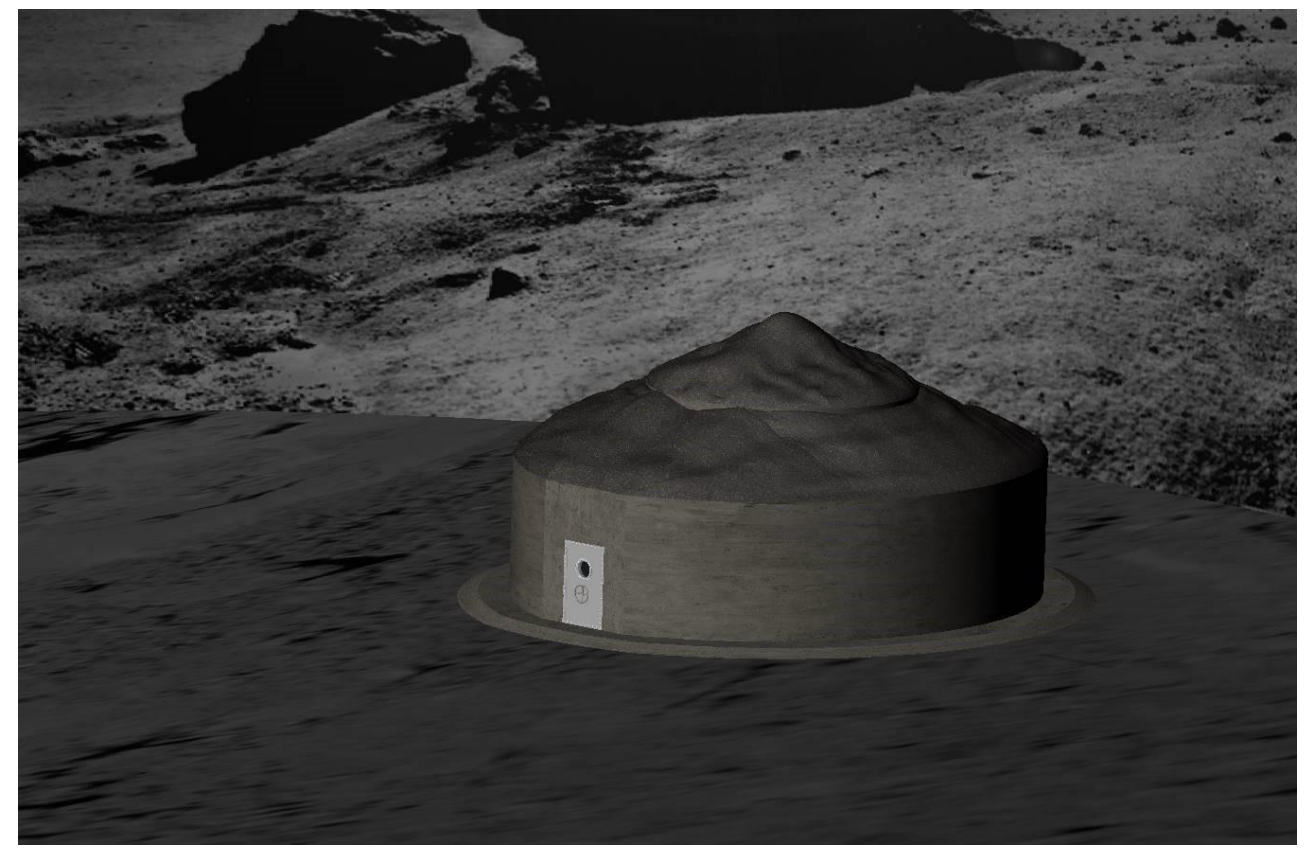

Fig. 14 Planetary Surface Habitat Design Concept for Additive Construction. Image used with permission from R. Robertson/J. Thomas.

The MSFC/Jacobs Space Exploration Group is continuing to evaluate design modifications required to fly an ACES-3-like system to a planetary surface for autonomous construction of surfaces structures. These modifications, while not an extensive list, are shown in Table 3.

Table 3 Design features under evaluation for planetary-based additive construction systems

\begin{tabular}{|c|c|}
\hline Weight reduction & Motor Selection (steppers vs servos) \\
\hline $\begin{array}{c}\text { Radiation hardening (to prevent SEU upsets and material } \\
\text { performance degradation) }\end{array}$ & $\begin{array}{c}\text { Translation options (rack \& pinion vs chain drive vs } \\
\text { friction drive vs ??) }\end{array}$ \\
\hline $\begin{array}{c}\text { Packaging/self deployment (assuming minimal astronaut } \\
\text { support) }\end{array}$ & Sealed materials transportation (dust/abrasion reduction) \\
\hline Site to site movement & $\begin{array}{c}\text { Sealed mixing of cementitious materials (dust/abrasion } \\
\text { reduction) }\end{array}$ \\
\hline
\end{tabular}

\section{Planetary Construction Materials Development}

One of the major factors in making deep space missions cost-effective is the ability to utilize materials found insitu. Construction materials created from in-situ resources would provide the ability to manufacturing habitats or other infrastructure elements (e.g., roads, berms, garages, wadis) on planetary surfaces at a relatively low cost. Additive construction assists in that effort by reducing the overall amount of material needed for the construction process. 
Materials available in-situ on the Moon and Mars (for example) are primarily basaltic in nature. However, each site on each planet is unique; the mineralogy and geochemistry of planetary materials varies from site to site. For example, the geochemistry and mineralogical abundances are different between the highlands and the mare of the Moon. On Mars, geologic processes including weathering provided areas of volcanic materials, river and lakebed sediments, evaporites, and Aeolian dunes to name a few. Volatile phases exist in some materials and in the Permanently Shadowed Regions of the Moon. Mars has a $\mathrm{CO}_{2}$-rich atmosphere, water-frost, and water-ice-bearing polar caps. It is from these volatile phases that many polymers can be fabricated.

Much of the materials research completed under the Additive Construction with Mobile Emplacement (ACME) project focused on Ordinary Portland Cement (OPC) because it is a readily available, relatively low cost material that can be used in terrestrial additive construction systems; it allows testing of specific hardware elements. Unfortunately, traditional OPC is not a viable planetary construction material for a variety of reasons. First, traditional components to make OPC are not available on the Moon (e.g., clays). Second, in the case of Mars, components can be mined but only from locations 1000's of km apart. Third, in-situ resources such as water will primarily be used for propulsion and life support, not for construction materials. Thus, the ACME Materials Team targeted the development of other types of binder materials (Table 4) with the goal of producing them from materials found in-situ, as well as minimizing the use of, or allowing the reclamation of, water.

Table 4 - Identified ISRU-Based Additive Construction Binders

\begin{tabular}{|l|l|}
\hline Ethylene vinyl alcohol $\left[\mathrm{EVOH},\left(\mathrm{C}_{2} \mathrm{H}_{4} \mathrm{O}-\mathrm{C}_{2} \mathrm{H}_{4}\right)_{n}\right]$ & Kerogen (hydrocarbons) \\
\hline Sodium silicate $\left(\mathrm{Na}_{2} \mathrm{SiO}_{3}\right)$ & Silicone $\left(\mathrm{C}_{6} \mathrm{H}_{5} \mathrm{SiO}\right)$ \\
\hline Polyethylene $\left[(\mathrm{C}, \mathrm{H})\left(\mathrm{C}_{2} \mathrm{H}_{4}\right)_{n}\right]$ & Geopolymers (various compositions) \\
\hline Water-ice $\left(\mathrm{H}_{2} \mathrm{O}\right)$ & Polyurethane $(\mathrm{N}, \mathrm{H}, \mathrm{C}, \mathrm{O}$ in different configurations) \\
\hline Ordinary Portland Cement $(\mathrm{CaO}-$ based) & Thermite (various metals) \\
\hline MgO-based (Sorel-type) Cement & Hydroxyapatite $\left[\mathrm{Ca}_{5}\left(\mathrm{PO}_{4}\right)_{3}(\mathrm{OH})\right]$ \\
\hline Sulfur & \\
\hline
\end{tabular}

One of the binder materials that allows reclamation of water is sodium silicate. Sodium silicate is the product of sodium hydroxide $(\mathrm{NaOH})$ and silica $\left(\mathrm{SiO}_{2}\right)$ in an aqueous solution. As a chemical precipitate, sodium silicate crystallizes as water is evaporated from the system. This drying process can allow water to be captured and recycled for further binder production use. Unfortunately, preliminary results indicate the highest compressive strength of the material is dependent on a small amount of water remaining within the matrix, which is unlikely to occur in a planetary environment (i.e., Mars) in which the atmospheric pressure is $1 / 100^{\text {th }}$ that of Earth's. Additionally, after numerous experiments with different curing regimen, grain sizes, and binder/aggregate ratios, the highest ultimate strength obtained for the sodium silicate mixture was less than 700psi.

Elemental sulfur continues to be investigated for use as an in-situ produced planetary regolith cementitious binder [23, 24]. Sulfur can constitute up to $0.3 \%$ by weight of a lunar high titanium mare basalt $[25,26]$, and has been found as sulfates and sulfides on Mars [27, 28]. The vapor pressure of sulfur is high enough that it sublimates on the surface of the Moon and (albeit slower) on Mars [23, 24]. Thus, sulfur is not an ideal exposed construction material for these planetary surfaces, but it can be used if a skin or liner prevents sublimation; this is an example of the additional items in a trade space for optimizing construction materials for planetary surfaces.

The team also investigated a magnesium oxide $(\mathrm{MgO}$, a readily available component of lunar and martian regolith), and monopotassium phosphate (MKP) binder. The mixtures contained different additives (boric acid, stucco mix, and fly ash) to establish the proper rheology for printing, but the ultimate compressive strength (Fig. 15) was weaker than OPC, and its hypervelocity impact resistance was not ideal for planetary surface environments [29]. Different $\mathrm{MgO}$-based cements are currently under study (e.g., $\mathrm{MgO}$ and magnesium chloride, magnesium oxysulfate).

The biggest challenge to the development of planetary construction materials is the environment in which the material will have to perform. Emplacement of a liquid material in a low vacuum (as in the case of Mars) or high vacuum (as in the case of the Moon) environment is difficult due to the vapor pressure of most materials - like sulfur, they tend to sublimate at such low pressures. 


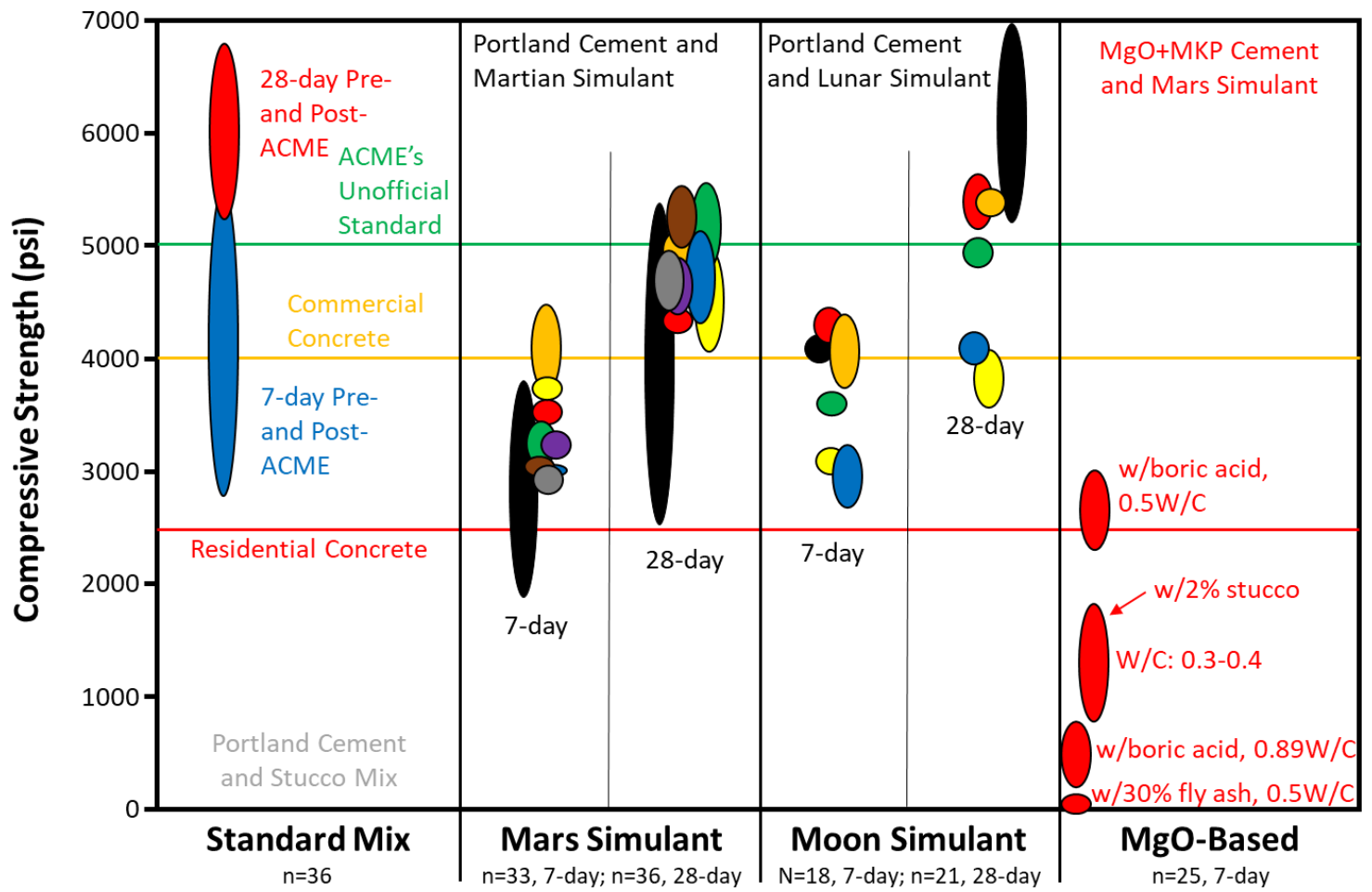

Fig. 15 Compressive strength of mixtures containing OPC (left and two center columns) and MgO+MKP (right column). The right column shows the standard mix results after standard ASTM C109 testing at 7 days for initial strength (formation of tricalcium silicate) and ultimate strength at 28 days (formation of dicalcium silicate). The two center columns show grain size results from martian and lunar regolith simulants at 7-days and 28-days. Black indicates unsieved material ( $5 \mathrm{~mm}$ and smaller grain sizes for martian simulant, $1 \mathrm{~mm}$ and smaller for lunar simulant). The smallest grains ( $<63$ microns) are represented by red, orange (63-125 microns), yellow (125-250 microns), green (250-500 microns), blue (500-1000 microns), purple (1000-2000 microns), brown (2000-4000 microns), and gray (4000-5000 microns). The notes in the right column indicate the type of additive. "w/" is "with" and W/C is the water to cement ratio.

Fig. 16 shows two such examples, one composed of OPC and martian regolith simulant cured in a Mars-like atmosphere at $20^{\circ} \mathrm{C}$, and a sodium silicate sample cured in a vacuum chamber at approximately $20^{\circ} \mathrm{C}$. Temperature swings in the environment are also a major concern. On the Moon near the equator, the temperature can range from $-178^{\circ}$ to $117^{\circ}$ Celsius. On Mars, Viking 1 measured $-89^{\circ}$ to $-31^{\circ}$ Celsius. An additional challenge is the extremely reducing environment on the Moon, due to the impact of hydrogen from solar wind, and the oxidizing environment on Mars due to the production and prevalence of perchlorates on the martian surface. Any material emplaced on the surface of the Moon or Mars must be designed for, and survive within, the environment.

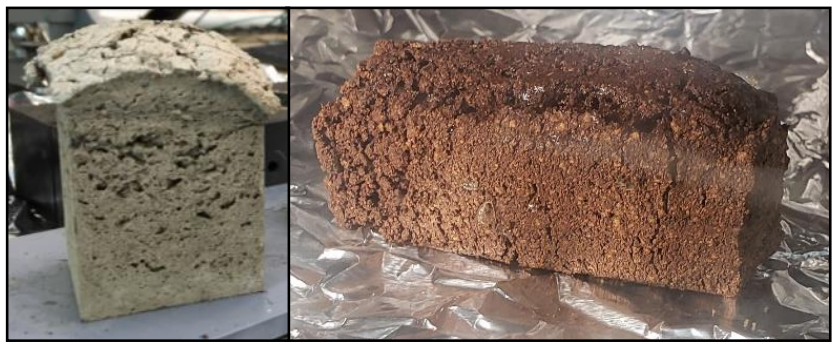

Fig. 16 Left, OPC and martian regolith simulant cured in a $\mathrm{CO}_{2}$ atmosphere at 7 torr and $20^{\circ} \mathrm{C}$ (photo included with permission from J. Edmunson). Right, sodium silicate and martian regolith simulant cured in a vacuum at approximately $20^{\circ} \mathrm{C}$ (image used with permission from J. Amar). Note large vesicle and crack formation due to the escape of water. 


\section{Conclusions}

For acceptance of $\mathrm{AC}$ as a viable terrestrial construction technique by building construction authorities including ASTM, standards for materials, specifications, design, manufacturing and testing must be developed. These standards and their appropriate application in design and construction must ensure that appropriate levels of reliability are achieved. This is equally important for planetary applications as well.

AC hardware development and operation is clearly not trivial, especially for miltary and NASA applications. The NASA/Jacobs Space Exploration Group team has made significant inroads into understanding the critical parameters associated with development of a robust additive construction system that can be relocated worlwide for miltary applications and, with appropriate modifications, can be used on the Moon and Mars as well. As construction becomes increasingly automated and less labor intensive, additive construction will be at the forefront in facilitating changes in which structures, both on Earth and on other planetary surfaces, are traditionally designed and fabricated. Additive construction truly is a disruptive technology in this regard.

\section{Acknowledgments}

The authors would like to thank NASA's Game Changing Development Program (GCDP) and the U.S. Army Corps of Engineering for their financial support during the development of the ACME and ACES additive construction systems. Special thanks to Raymond (Corky) Clinton for his unwavering support of the ACME project. The authors also acknowledge the efforts of :

Materials Development - Samantha Frederick, Joe Amar, Dr. Hunain Alkhateb (Ole Miss), Dr. Amin Akhnoukh (East Carolina University), Mina Akhnoukh

Mechanical Design - Allyson Thomas, Jack Thomas, Todd Swearingen, Jeffrey Lawson, Lauren Badia

Electrical Design \& Test - L.D. Stewart, Jeff Richeson, Kosta Varnavas

Assembly \& Test - Tintsey Coats, Mark Sloan, John Tucker, Nancy Wilbanks, Joey Malone, Van Townsend, Catherine Bell

Procurement - Debra Balsama, Kim Edmondson

\section{References}

[1] Christensen, C.M., (1997). The Innovator's Dilemma, Harvard Business School Press.

[2] Warszawski, A., and Navon, R., "Implementation of Robotics in Building: Current Status and Future

Prospects," Journal of Construction Engineering and Management, 124 (1998), 31-41.

[3] Jha, K. N., "Formwork for Concrete Structures," Tata McGraw Hill Education Private Limited, New Delhi, India (2012), ISBN (13): 978-1-25-900733-0.

[4] Available from: https://contourcrafting.com [Accessed April 2018.]

[5] Fiske, M.R., et al., "Lunar In Situ Materials-Based Surface Structure Technology Development Efforts at NASA/MSFC," Proceedings of the Space Technology and Applications International Forum (STAIF), Albuquerque, NM, 2007.

[6] Khoshnevis, B., and Bekey, G., "Automated Construction Using Contour Crafting: Applications on Earth and Beyond," in proceedings of the $19^{\text {th }}$ International Symposium on Automation and Robotics in Construction, National Institute of Standards and Technology, Gaithersburg, MD, September 23-25, 2002, pp 489-494.

[7] Khoshnevis, B., Bodiford, M.P., Burks, K.B., Ethridge, E., Tucker, D., Kim, W., Toutanji, H., and Fiske, M.R., "Lunar Contour Crafting - A Novel Technique for ISRU-Based Habitat Development," in proceedings of the $43^{\text {rd }}$ AIAA Aerospace Sciences Meeting and Exhibit, American Institute of Astronautics and Aeronautics, Reston, VA, 2005, Paper AIAA-2005-0538.

[8] Langenberg, 2015. Available from: http://www.3dprintingarchitecture.net/?p=601, posted 20/03/2015 [Accessed December 2017].

[9] Bodiford, M.P., Fiske, M.R., McGregor, W., and Pope, R.D., "In Situ Resource-Based Lunar and Martian Habitat Structures Development at NASA/MSFC," in proceedings of the AIAA $1^{\text {st }}$ Exploration Conference, American Institute of Astronautics and Aeronautics, Reston, VA, 2005, Paper AIAA-2005-2704.

[10] Roussel, N., and Cussigh, F., Distinct Layer Casting of SCC: The Mechanical Consequences of Thixotropy, 
Cem Concr Res, 38: 624-632, 2008.

[11] Wangler, T., Lloret, E., Reiter, L., Hack, N., Gramazio. F., Kohler, M., Bernhard, M., Dillenburger, B., Buchli, J., Roussel, N., and Flatt, R., Digital Concrete: Opportunities and Challenges, RILEM Technical Letters, 1: 6775 (2016).

[12] Fiske, M. R. and Khoshnevis, B., ACES-3 Mobility System Trade Study, unpublished work under NASA Contract Number NNM16568754R, 2016.

[13] Suvash C.P., Gideon P.A.G. van Zijl, M. J. Tan, and I. Gibson, (2018) "A review of 3D concrete printing systems and materials properties: current status and future research prospects", Rapid Prototyping Journal, Vol. 24 Issue: 4, pp.784-798, https://doi.org/10.1108/RPJ-09-2016-0154

[14] Kwon, H., "Experimentation and Analysis of Contour Crafting (CC) Process Using Uncured Ceramic Materials (Electronic)," PhD Thesis, University of Southern California, USA (2002).

[15] Anell, L. H., “Concrete 3D Printer,” MSc Thesis, Civil Engineering, Lund University, Sweden (2015)

[16] Available from: https://en.wikipedia.org/wiki/LinuxCNC, [Accessed February 2018.]

[17] Mueller, R.P., Fikes, J.C., Case, M.P., Khoshnevis, B., Fiske, M.R., Edmunson, J.E., Kelso, R., and Romo, R., Additive Construction with Mobile Emplacement (ACME), $68^{\text {th }}$ International Astronautical Congress (IAC), Adelaide, Australia, 25-29 September 2017.

[18] Labonnote, N., et al., Additive Construction: State-of-the-Art, Challenges and Opportunities, Automation in Construction (2016), http://dx.doi.org/10.1016/j.autcon.2016.08.026.

[19] Lim, S., Bus well, R.A., Le, T.T., Austin, S.A., Gibb, A.G.F., and Thorpe, T., Developments in ConstructionScale Additive Manufacturing Processes, Automation in Construction, 21(1), pp. 262-268 (2012)

[20] Kazemian, A., Yuan, X., Meier, R., Cochran E., and Khoshnevis, B., "Construction-Scale 3D Printing: Shape Stability of Fresh Printing Concrete", Proceedings of the ASME $201712^{\text {th }}$ International Manufacturing Science and Engineering Conference (MSEC2017-2823), June 4-8, 2017, Los Angeles, CA.

[21] Zareiyan, B., and Khoshnevis, B., "Effects of Interlocking on Interlayer Adhesion and Strength of Structures in 3D Printing of Concrete", Automation in Construction 83 (2017) 212-221, http://dx.doi.org/10.1016/j.autcon.2017.08.019.

[22] "WinSin China Builds Worlds First 3D Printed Villa and Tallest 3D Printed Apartment Building," http://www.3ders.org, retrieved on 25 April, 2018.

[23] R. N. Grugel and H. Toutanji (2016) Sulfur "concrete" for lunar applications - Sublimation concerns. Advances in Space Research 41, 103-112.

[24] L. Wan, R. Wender and G. Cusatis (2016) A novel material for in situ construction on Mars: Experiments and numerical simulations. Construction and Building Materials 120, 222-231.

[25] E.J. Gibson, Jr. and G.W. Moore (1974) Sulfur abundances and distributions in the valley of Taurus-Littrow. Proceedings of the $5^{\text {th }}$ Lunar Science Conference, 1823-1837.

[26] D. Vaniman, D. Pettit, and G. Heiken (1992) Uses of lunar sulfur. $2^{\text {nd }}$ Conference on Lunar Bases and Space Activities, 429-435.

[27] A. Gendrin, N. Mangold, J. P. Bibring, Y. Langevin, B. Gondet, F. Poulet, G. Bonello, C. Quantin, J. Mustard, R. Arvidson, and S. LeMouelic (2005) Sulfates in martian layered terrains: The OMEGA/Mars Express View. Science 307, 1587-1591.

[28] J. J. Wray, E. Z. Noe Dobrea, R. E. Arvidson, S. M. Wiseman, S. W. Squyres, A. S. McEwen, J. F. Mustard, and S. L. Murchie (2009) Phyllosilicates and sulfates at Endeavour Crater, Meridiani Planum, Mars. Geophysical Research Letters 36(L21201). DOI: 10.1029/2009GL040734

[29] E. Ordonez, J. Edmunson, M. Fiske, E. Christiansen, J. Miller, B. Davis, J. Read, M. Johnston, and J. Fikes (2017) Hypervelocity impact testing of materials for additive construction: Applications on Earth, the Moon, and Mars. Procedia Engineering. Doi: 10.1016/j.proeng.2017.09.787. 